\title{
Thermal Insulation of Residential Construction through the Study of Temperature Difference of Bricks
}

\author{
Sayang Syazanna Raf'ee ${ }^{1}$, Mohd Shahir Liew ${ }^{1, *}$, Noor Amila Zawawi ${ }^{1}$, and Kamaluddeen \\ Usman Danyaro ${ }^{2}$ \\ ${ }^{1}$ Department of Civil and Environmental Engineering, Universiti Teknologi PETRONAS, 32610 \\ Seri Iskandar, Perak, Malaysia \\ ${ }^{2}$ Offshore Engineering Centre, Universiti Teknologi PETRONAS, 32610 Seri Iskandar, Perak, \\ Malaysia
}

\begin{abstract}
This study seeks to measure the temperature difference of 3 types of interlocking bricks and 2 types of conventional bricks, all which are available in Malaysian market. The study aims to assist Malaysia's residential construction dilemma in masonry. This is done by constructing 5 models using different types of bricks with the same dimensions, finishes and placed in the same area. Six points were taken to measure the temperature differences. The equipment used are 6 Thermocouples and HOBO UX120-014M data logger. Intervals of 15 minutes were recorded with duration of four months in Tronoh, Perak. Results show the best performed brick is IB2, even though IB1 and Clay bricks depict significant temperature differences. Comparing the temperature differences of IB1 and Clay brick, IB1 provide a better performance in a hot weather due to its higher thermal conductivity.
\end{abstract}

\section{Introduction}

The temperature differences of locally manufactured bricks are studied to justify its thermal performance for residential construction. Since Malaysia is a developing country, more residential construction is expected. A high indoor temperature results to a lower indoor environmental quality, resulting high energy use of mechanical system for thermal control [1]. Meanwhile, thermal insulating materials are expensive as they are used for fire safety of insulating host weather for buildings, which results to higher costs and hazardous to the environment than bricks [2-4]. In addition, studies are scarce in identifying and comparing the temperature differences of locally manufactured interlocking bricks and conventional bricks. Previous studies regarding interlocking bricks have been promising. Therefore, this study hopes to validate its potential. The temperature difference of three interlocking bricks and two conventional bricks are compared and recorded using thermocouples and a data logger. Thus, results show Clay bricks provided better results than interlocking bricks. The paper shall expatiate with the literature review related to this study, followed by the

*Corresponding author: shahir_liew@utp.edu.my 
methodology used to measure the temperature difference, the discussions of results and end with a conclusion.

\section{Literature review}

\subsection{Carbon emission of residential construction}

According to Xiodang et. al [6], a life-cycle of carbon emission can be found during the operation stage which can reach approximately $32 \%$ of global final energy consumption and $30 \%$ being energy related of $\mathrm{CO}_{2}$ emission. This was then supported by the U.S EIA in 2004 that residential construction does contribute to $21 \%$ out $48 \%$ of total emission made by a building [7]. Memari et.al. [8], analyzed that the housing sector needs improvements in many areas, which includes embracing green and sustainable design and construction. However, it is also indicated that a research has been done to reduce the construction impacts by concentrating on three main areas which are; use of reclaimed materials, local sourcing and materials selection [9].

\subsection{Sustainable development}

The United Nations Framework on Climate Change [10] states that sustainable construction is a road that can help developing countries in promoting sustainable development. This was supported by Chetan et al and Levine et al $[11,12]$, that the construction industry is a major consumer of natural resources, thus, sustainable construction strategy should include all parameters to reduce energy and atmospheric carbon emission [11,12]. In Malaysia's perspective, the step towards sustainable development started from the Ninth Malaysian Plan (2001-2005) [13], where the progress and prospects of Housing were addressed. To support said motion, in 2009, the Ministry of Energy, Green Technology and Water (MEGTW or KeTTHA), conditioned that any construction that receives a Green Building Index (GBI) certificate after the end of its assessment shall be given an incentive of tax and stamp duty exemption [14]. According to Chua et. al. [15], due to the support and intervention of the government, green awareness among the public and private sectors are rapidly encouraging; especially by providing green awareness and various incentives offered while enacting green policies

\subsection{Masonry}

Building materials can be associated with the major environmental burden as each building materials (conventional and innovative types) have embodied energy while having GHG emission originated from each stage of life. If looked through a Life-Cycle Analysis of masonry, a brick can contribute to the sustainable design by looking through the materials used, how it is made, manufactured and used [16]. It was indicated that bricks used in residential buildings can be designated as a walling element, partition as well as architectural elements [17]. However, the ability of bricks to regulate indoor temperature is because of its thermal mass properties [18]. This is supported by a study stating bricks can be cooler in the hottest part of the day and warmer during the night [19].

\subsection{Interlocking bricks}

The current mitigation made and discovered for masonry in Malaysia are Interlocking Bricks. The technique for Interlocking Brick which provides a lock and key system, has 
gained popularity first in Thailand, Philippines and Malaysia way back to the 1960's. Thus, the professionals in the building industry in Asian countries are showing high preference for the use of interlocking masonry as compared with the conventional types [20]. Significantly, it was stated that Interlocking Bricks has been described as one of the simplest, flexible and most versatile system [21]. However, the uses of Interlocking Bricks in Malaysia are not preferable since there are no specific standard to the system [22]. To add, studies are scarce in production and installation of the system based on local requirements. This results it to be hindered to use in the construction industry. There are also limited studies of interlocking bricks with regards to the heat flow of available interlocking bricks in Malaysian market.

\section{Methodology}

\subsection{Experimentation}

In this study, an experiment is conducted to work on 3 types on interlocking bricks brought locally in Malaysia. This method is studied from Chaimoon et.al [23] and Yong et.al [24], depicting that interlocking bricks have a better thermal conductivity than clay. The limitation of this study is due to the limited space provided. Thus, contributing it to be scaled down to $1000 \mathrm{~mm}$ (l) x $500 \mathrm{~mm}(\mathrm{w})$ x $300 \mathrm{~mm}$ (h). Initially, a double-story terrace house in Selangor had taken. The test models were placed at on open area near the Sewage Treatment Plant in Universiti Teknologi PETRONAS. The experiment consists as below;

a) Each model is constructed using typical construction practices.

b) Mortar plastering at interior and exterior of wall.

c) Roof cover shall be concrete tile roof and ply wood.

d) 2 thermocouples placed in interior and exterior of at the center of wall (TC2-TC4).

e) 1 thermocouple placed in middle of model (TC1).

f) 1 thermocouple placed away from model (TC4).

Data from thermocouple were collected by HOBO UX120 4-Channel Thermocouple Logger. The wall surfaces together with the internal and external temperature are recorded in a 15 minutes interval for the duration of five (5) months for accuracy and are periodically checked monthly. Each visit is recorded to reduce the probability of error that may occur in the researchers' absence. The placements of thermocouples are depicted in Figure 1. The data logger is placed on each test model labelled as IB1, IB2, IB3, Cement Sand and Clay Brick and executed.

\subsection{Material properties}

As previously mentioned, all bricks were taken locally in Malaysia. Interlocking Bricks were taken from manufacturers in Selangor while conventional bricks were brought from the local hardware store. As mentioned, clay bricks and cement sand block are the most used as structural masonry [25]. Thus, these conventional types are considered. The selected Interlocking Bricks and its properties are presented in Table 1 and Figure 3.

Table 1. Properties of brick used

\begin{tabular}{|l|l|c|}
\hline \multicolumn{1}{|c|}{ Type of Brick } & \multicolumn{1}{c|}{ Material } & Size (mm) \\
\hline IB1 & Clay, Sand, Cement & $250 \times 125 \times 100$ \\
\hline IB2 & Cement, Quarry Dust, Chippings & \multirow{2}{*}{$200 \times 100 \times 100$} \\
\cline { 1 - 2 } IB3 & Cement Sand & \\
\hline Cement Sand Brick & Clay & \\
\cline { 1 - 2 } Clay Brick &
\end{tabular}




\section{Results and discussions}

\subsection{Temperature distribution}

Table 2 depicts the results of Interlocking Bricks and Conventional Bricks of a 5-month data collection with every data sampled every 15 minutes. From the overall results, it can be summarized that every temperature difference of bricks experienced a higher internal/inner wall temperature compared to external/outer wall temperature.

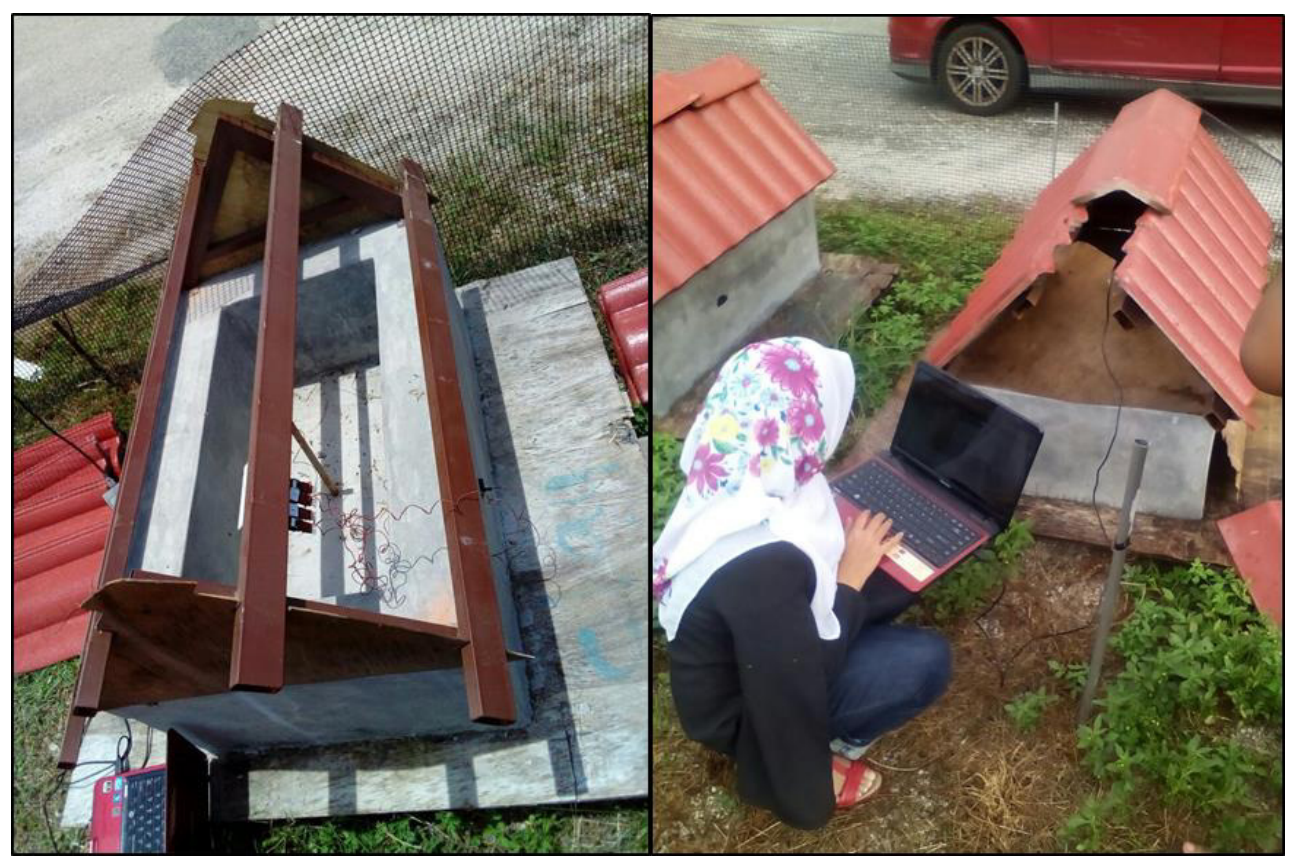

Fig. 1. Placement of thermocouples (TC1, TC2, TC3 and TC4) on a test model

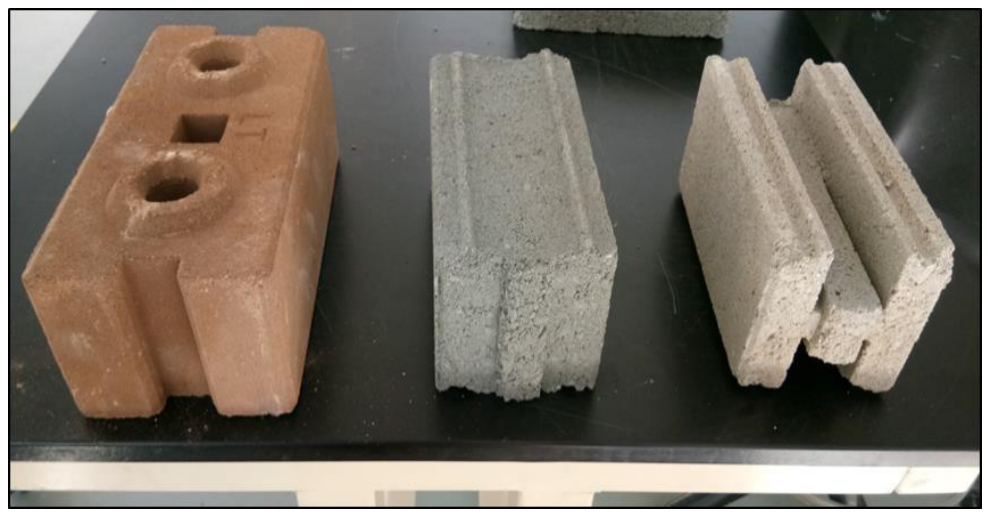

Fig. 2. Interlocking Bricks selected; IB1, IB2 and IB3 
The may be due to the poor roof insulation since for this research, no insulation was done for the roof. As stated, besides night ventilation and window and wall shading, roof insulation may be able to be a mitigation method as a vernacular passive cooling technique for terrace houses in Malaysia [26]. This helps reduce the internal circulation and providing a lower temperature internally of a building/structure.

From the observation of its mean, median and mode, every internal, external, inner wall and outer wall temperature of every bricks displayed a mean greater than its median which is greater than its mode, hence depicts a positive skew. However, for the temperature differences results for each brick, the mean, median and mode does not represent a positive skew. This may be due to its high variation as depicted by its standard deviation and coefficient of variation, since both values are more than one (1). A coefficient of variation, which has a value more or equal than 1, show a high variance [27]. Therefore, a larger sample size is needed to find a significant difference.

Overall each brick shows a potential in reducing temperature from the outside to the inside. Furthermore, its standard of deviation is not very far off from each other. However, the most obvious is the coefficient of variation of IB2 which is the lowest and nearer to zero (0) while the others are more than five (5). In addition, the mode for IB2 is also small ($0.5)$. Thus, IB2 gave the best results.

IB1 and Clay Bricks gave better temperature differences results; this may be due to having Clay as its main material content. Although studies have proven Clay being a main component in providing better thermal comfort, but studies have shown that in terms of carbon emission, Clay bricks show the highest value of energy to produce as it requires a lot of energy to burn in the kiln [28].

Although IB2 and IB3 have the same material, the difference of its lock and key system does contributes to the results of its temperature difference. Even though the standard of deviation is nearly the same, the coefficient of variation differs tremendously as IB3 is higher than IB2 albeit having better temperature differences. This depicts that IB3 have a higher variation than IB2. Thus, too much variation does not ensure a stable temperature difference, which also indicates the probability of having a hotter temperature inside the building/structure. In selection between these two Interlocking Bricks of the same material, IB2 displays a better result in providing a better temperature difference.

Table 2. Temperature distribution of interlocking bricks and conventional bricks

\begin{tabular}{|c|c|c|c|c|c|c|c|c|c|}
\hline \multicolumn{3}{|c|}{ Type of Brick } & MEAN & MEDIAN & MODE & $\overline{\text { MAX }}$ & SDV & MIN & $\mathrm{CV}$ \\
\hline \multirow{6}{*}{ IB1 } & TC2 & $\begin{array}{c}\text { Interior } \\
\text { Wall }\end{array}$ & 29.08 & 28.32 & 26.37 & 47.85 & 3.3013 & 22.24 & 0.1135 \\
\hline & TC3 & $\begin{array}{c}\text { Exterior } \\
\text { Wall }\end{array}$ & 29.82 & 27.83 & 25.32 & 52.76 & 5.5148 & 21.89 & 0.1849 \\
\hline & & Difference & 0.7434 & -0.6 & $\begin{array}{l}-0.84 \\
\end{array}$ & 22.96 & 4.0232 & -8.51 & 5.4120 \\
\hline & TC1 & Inner Wall & 28.75 & 27.63 & 25.68 & 42.95 & 3.7898 & 22.09 & 0.1318 \\
\hline & TC4 & Outer Wall & 28.64 & 26.58 & 24.30 & 56.44 & 5.1387 & 21.71 & 0.1794 \\
\hline & & Difference & -0.1025 & -0.76 & -1.18 & 20.87 & 2.3570 & -9.12 & $\begin{array}{c}22.987 \\
4\end{array}$ \\
\hline \multirow{6}{*}{ IB2 } & TC2 & $\begin{array}{c}\text { Interior } \\
\text { Wall }\end{array}$ & 29.57 & 28.37 & 25.49 & 44.27 & 4.3912 & 20.39 & 0.1485 \\
\hline & TC3 & $\begin{array}{c}\text { Exterior } \\
\text { Wall }\end{array}$ & 30.47 & 28.75 & 25.37 & 46.06 & 5.3924 & 22.32 & 0.1770 \\
\hline & & Difference & 0.90 & -0.3 & -0.45 & 14.68 & 2.7123 & -4.55 & 3.0359 \\
\hline & TC1 & Inner Wall & 28.71 & 27.29 & 24.74 & 42.41 & 4.3351 & 17.08 & 0.1510 \\
\hline & TC4 & Outer Wall & 28.13 & 26.477 & 24.26 & 43.93 & 4.2909 & 21.40 & 0.1525 \\
\hline & & Difference & -0.5771 & -0.67 & -0.5 & 12.52 & 1.7294 & -9.53 & 2.969 \\
\hline IB3 & TC2 & Interior & 29.79 & 28.32 & 25.72 & 43.66 & 4.7247 & 22.43 & 0.1586 \\
\hline
\end{tabular}




\begin{tabular}{|c|c|c|c|c|c|c|c|c|c|}
\hline & & Wall & & & & & & & \\
\hline & TC3 & $\begin{array}{c}\text { Exterior } \\
\text { Wall }\end{array}$ & 30.84 & 28.61 & 25.18 & 48.76 & 6.1213 & 22.22 & 0.1985 \\
\hline & & Difference & 1.05 & -0.34 & -0.43 & 15.30 & 3.0329 & -4.8 & 2.9015 \\
\hline & TC1 & Inner Wall & 28.07 & 26.8 & 24.27 & 44.21 & 3.8198 & 21.74 & 0.1361 \\
\hline & TC4 & Outer Wall & 28.10 & 26.31 & 24.37 & 42.28 & 4.3233 & 21.51 & 0.1539 \\
\hline & & Difference & 0.02 & -0.41 & -0.41 & 9.09 & 1.8113 & -9.1 & $\begin{array}{c}81.882 \\
1\end{array}$ \\
\hline \multirow{6}{*}{$\begin{array}{l}\text { Cem } \\
\text { ent } \\
\text { Sand }\end{array}$} & TC2 & $\begin{array}{c}\text { Interior } \\
\text { Wall }\end{array}$ & 29.69 & 28.49 & 25.72 & 44.09 & 4.3529 & 22.47 & 0.1466 \\
\hline & TC3 & $\begin{array}{c}\text { Exterior } \\
\text { Wall }\end{array}$ & 30.43 & 28.73 & 25.04 & 47.31 & 5.3383 & 22.35 & 0.1754 \\
\hline & & Difference & 0.74 & -0.41 & -0.57 & 14.17 & 2.8080 & -5.14 & 3.8328 \\
\hline & TC1 & Inner Wall & 28.76 & 27.61 & 26.37 & 43.14 & 3.8208 & 22.59 & 0.1328 \\
\hline & TC4 & Outer Wall & 28.39 & 26.73 & 24.19 & 50.36 & 4.6836 & 21.62 & 0.1650 \\
\hline & & Difference & -0.3683 & -1 & -1 & 18.78 & 2.7692 & -9.35 & 7.5188 \\
\hline \multirow{6}{*}{ Clay } & TC2 & $\begin{array}{c}\text { Interior } \\
\text { Wall }\end{array}$ & 29.50 & 28.33 & 25.65 & 43.79 & 4.1820 & 22.44 & 0.1418 \\
\hline & TC3 & $\begin{array}{c}\text { Exterior } \\
\text { Wall }\end{array}$ & 30.75 & 28.34 & 25.32 & 56.87 & 6.6380 & 22.18 & 0.2064 \\
\hline & & Difference & 1.25 & -0.54 & -0.5 & 25.02 & 4.3742 & -7.56 & 3.4777 \\
\hline & TC1 & Inner Wall & 28.4129 & 27.06 & 24.63 & 42.81 & 4.0329 & 21.67 & 0.1419 \\
\hline & TC4 & Outer Wall & 28.3328 & 26.25 & 24.27 & 62.84 & 5.1536 & 21.05 & 0.1819 \\
\hline & & Difference & -0.0801 & -0.59 & -0.5 & 26.96 & 2.5223 & -5.6 & $\begin{array}{c}31.475 \\
7\end{array}$ \\
\hline
\end{tabular}

All bricks gave standard variations that are higher than every mean. This depicts that all data sampled have a relatively high variation. Despite having high variation, each brick data sample shows a positive skew which means there are more low temperature differences than high temperature difference. Thus, the impact of both types of bricks; interlocking or conventional, are not much significant.

\subsection{Highest temperature difference}

From the results of the inner wall versus outer wall temperature difference, it is safe to say that each brick reduces the temperature from the outside to the inside of the model. Since IB1 and Clay Bricks presented better temperature differences to observe the difference more clearly, the results are presented together to observe its performance during the same selected date. Figure 3 and Figure 4 depict the highest temperature difference recorded upon a 5 (five) months of data sampling for Interlocking Bricks which is on the $3^{\text {rd }}$ of February 2017 by IB1 on 2:04 PM Malaysian time. Meanwhile, Figure 5 and Figure 6 depict the highest temperature difference for Conventional Bricks and on $16^{\text {th }}$ of February 2017 at 12:25 PM for Clay Bricks.

In the researcher's perspective, the likelihood of the high temperature difference is due to the position of sun being on its peak hour. Furthermore, both of the test models of both of these bricks are placed at each end in their location, thus absorbing an amount of heat more than test models that are placed in the middle. Based on the World Weather Online, the weather during 3rd of February 2017 shows the weather was very hot with only 19\% of cloud [29].

While on the $17^{\text {th }}$ of February, the weather was tolerable with a little bit of rain and $27 \%$ of cloud. Furthermore, this may be due to the thermal conductivity of material of said bricks. 
The thermal conductivity of IB1 is much higher than Clay Bricks. Thus, the higher the thermal conductivity, the faster the heat transmitted through the material. Hence, combining these two factors, the heat transferred for IB1 on a very hot weather shows significantly compared to a shady day. This differs differently with Clay bricks as it performs better if the weather is cloudy or rainy.

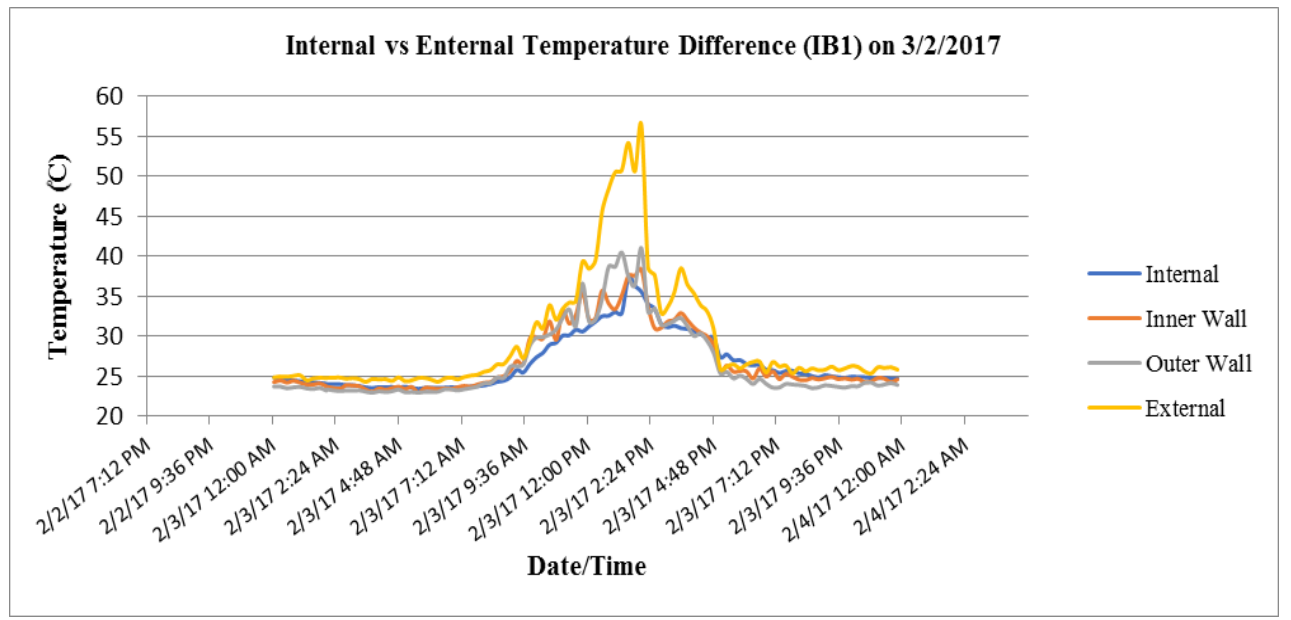

Fig. 3. Internal versus External Temperature Difference on $3^{\text {rd }}$ February 2017 for IB1

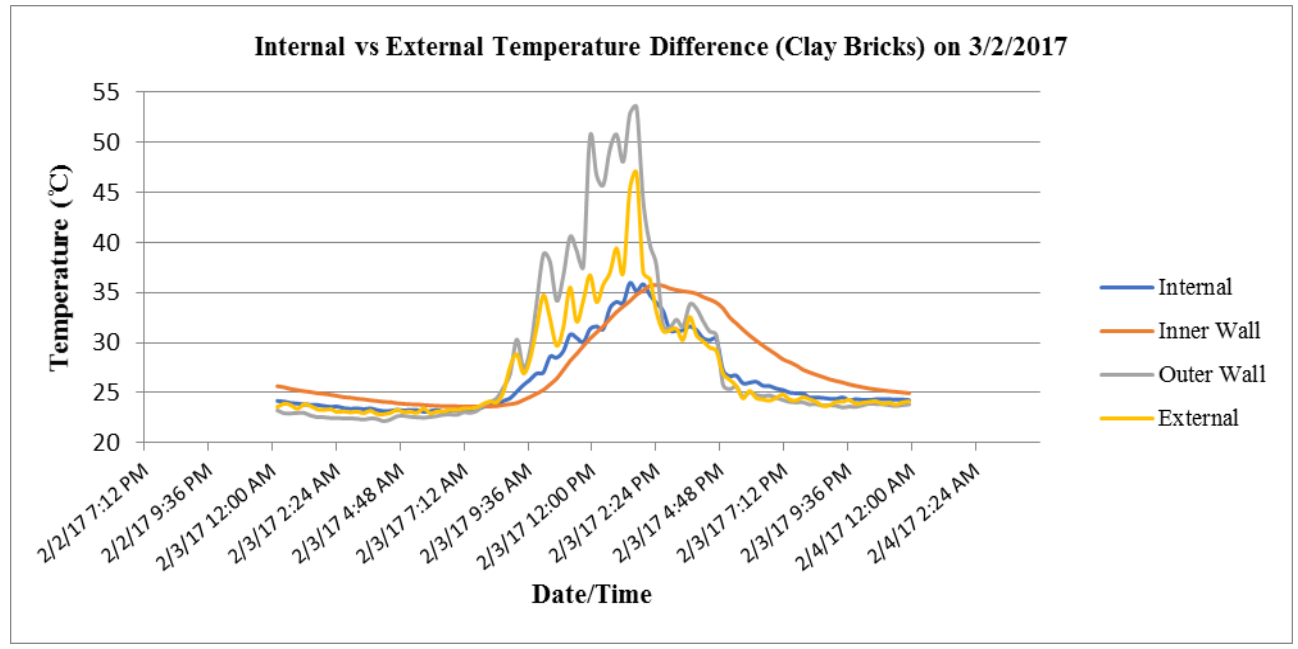

Fig. 4. Internal versus External Temperature Difference on $3^{\text {rd }}$ February 2017 for Clay Brick 


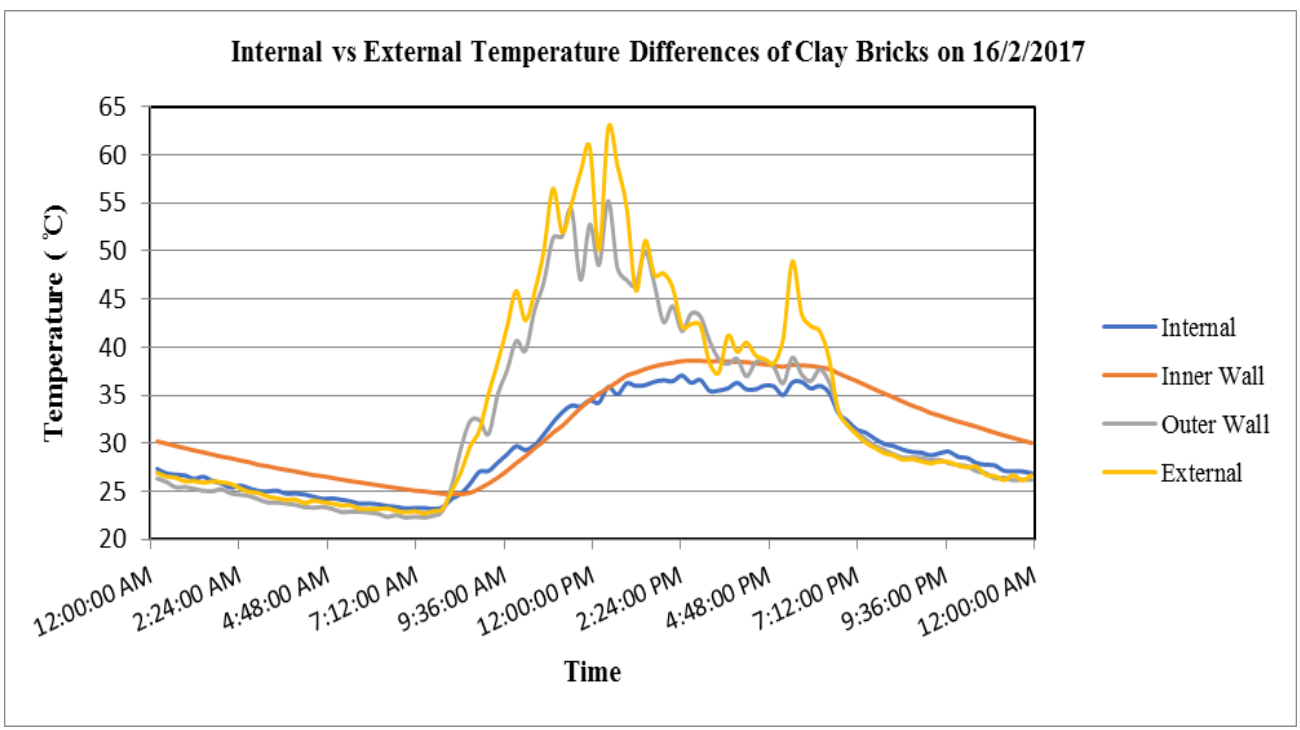

Fig. 5. Internal versus External Temperature Difference on $17^{\text {th }}$ February 2017 for Clay Brick

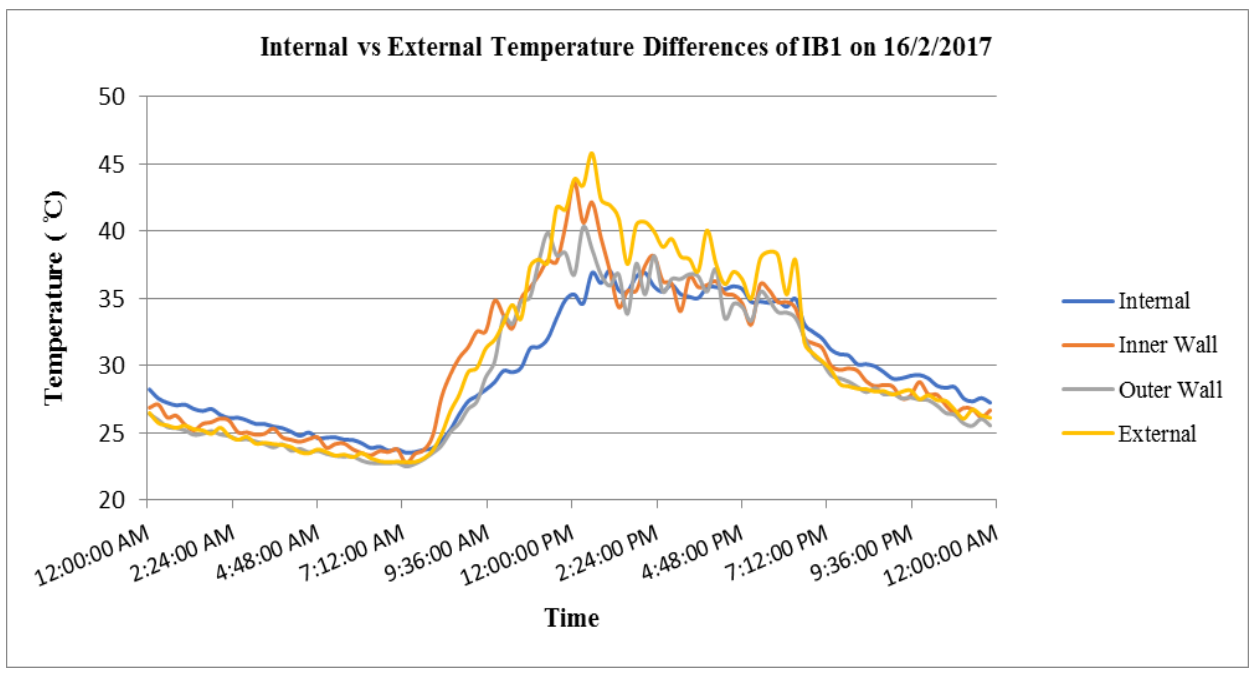

Fig. 6. Internal versus External Temperature Difference on $17^{\text {th }}$ February 2017 for IB 1

\section{Conclusion}

Findings suggest that the highest temperature difference was gained by Clay bricks, followed by IB1, IB3, IB2 and Cement Sand bricks. However, from the overall temperature distribution, even though each brick resulted to a positive skew, the results of the overall temperature differences states otherwise. This is due to the high coefficient of variation than standard deviation; hence the probability to achieve said temperature is unlikely. Each brick presented results to reduce temperature from the outside to the inside of the wall, but IB2 depicts the best choice. This is given by the lowest coefficient of variation and having a small mode. It also shows that the probability to achieve a low temperature is more likely and repetitively compared to other bricks. The material in bricks also affects its 
performance. This can be seen with the material content of Clay bricks and IB1 by giving a significant temperature difference. Apparently, due the difference of thermal conductivity, where IB1 has a higher thermal conductivity than Clay bricks, IB1 presented a better performance on a hot day. The difference in the lock and key system also affects the results of temperature difference as can be seen with IB2 and IB3. The findings in this study could be used for comparison evaluation of locally available manufactured Interlocking Bricks on its effectiveness on temperature differences. Study suggests a bigger scaled dimension on a real room scale for a more complex and accurate evaluation on temperature differences, as well as adding more points/ placements of thermocouples at different wall levels.

\section{Acknowledgement}

The authors would like to thank MOHE for funding the presentation of this paper at the conference using the project: FRGS 2015-1 (0153AB-K85).

\section{References}

1. D.L. Zr, S.Mochtar, Application of bioclimatic parameter as sustainability approach on multi-story building design in tropical area, Procedia Environmental Sciences 17, 822830 (2013)

2. M.Imran, M.S.Liew and M.S.Nasir, Experimental Studies on Fire for Offshore Structures and its Limitations: A Review, Chemical Engineering 45 (2015)

3. M.Imran, M.S.Liew, E.Garcia, M.Nasif, A.Yassin and U.Niazi, Deformation and Heat Transfer on Three Sides Proteted Beams under Fire Accident, IOP Conference Series: Earth and Environmental Science, 012122 (2018)

4. M.Imran, M.S.Liew, M.S.Nasif, U.M.Niazi and A.Yasreem, Hazard Assessment Studies on Hydrocarbon Fire and Blast: An Overview, Advanced Science Letters 23, 1243-1247 (2017)

5. M.Imran, M.S.Liew, M.S.Nasif, U.M.Niazi and A.Yasreen, Hydrocarbon Fire and Explosion's Safety Aspects to Avoid Accident Escalation for Offshore Platform, ICIPEG,801-808 (2017)

6. L. Xiaodang Li, Y.Fan, Z. Yimin, G.Yuanxue., An assessment framework for analyzing the embodied carbon impacts of residential buildings in China, Energy and Buildings 85, 400-409 (2014)

7. J.Wood, The Green House: Barriers and Breakthroughs in Residential Green Building, M.A Dissertation, Tufts University, US (2007)

8. A.M Memari, P.H. Huelman,, L.D. Iulo, J. Laquatra, C.Martin.,A. McCoy, I. Nahmens, T. Williamson, Residential Building Construction: State-of-the-Art Review, Journal of Architectural Engineering 20(4) (2014)

9. N.O'Loughlin, Crbon Constraints on the Construction Industry, PM Group. Environmental Services,ECOCEM (2008)

10. IPCC. Climate Change 2014: Mitigation of Climate Change, Chapter 4 Sustainable Development and Equity (2014)

11. S.D.Chetan, R.V. Ralegaonkar, A.Vaidehi, Design and Development of Sustainable Construction Strategy for Residential Buildings: A Case Study for Composite Climate, 
International Journal of Sustainable Construction Engineering \& Technology 4(1) (2013)

12. M.Levine, D.Ürge-Vorsatz, K. Blok, L. Geng, D. Harvey, S. Lang, G. Levermore, A. Mongameli Mehlwana, S. Mirasgedis, A. Novikova, J. Rilling, H. Yoshino, Residential and commercial buildings in Climate Change, Fourth Assessment Report of the Intergovernmental Panel on Climate Change. 6, 388- 446. (2007)

13. The Ninth Malaysian Plan 2006-2010. 444- 448. (The Economic Planning Unit, Prime Minister's Department, Putrajaya, Malaysia, 2006)

14. KeTTHA, Incentives for Renewable Energy, Energy Efficiency \& Green Buildings in Malaysia, 13-16. (2010)

15. S.C.Chua, T.H Oh, Green progress and prospect in Malaysia, Renewable and Sustainable Energy Reviews 15.2850-2861(2011)

16. I.El-adaway, T Breakah, S.Khedr, Brick Masonry and Sustainable Construction, IC SDC-2011, pp 524-534. (2012)

17. R.B, Ham. Masonry, Brick and Block Construction, Residential Construction Academy, Delmar Cengage Learning, Kentucky (2007)

18. E.Allen., J. Iano Fundamentals of Building Construction: Materials and Methods (Wiley, 2009)

19. M.Dondi, F.Mazznti, P.Principi,M.Raimando,G.Zanarini, Thermal Conductivity of Clay Bricks, Journal of Materials in Civil 16(1). pp. 8-14 (2004)

20. W. Karl, Building with Interlocking Blocks, Wall Building Technical Brief. (1995)

21. O.Oluwole, J.Joshua, H. Nwagwo, Finite Element Modeling of Low Heat Conducting Building Bricks, Journal of Minerals and Materials Characterization and Engineering 11.800-806. (2012)

22. Z.Ahmad, B.M. Yunus, A.Mohamed. Behaviour of Masonry Wall Constructed using Interlocking Soil Cement Bricks, International Journal of Civil, Environmental, Structural, Construction and Architectural Engineering 5(12). 804-810 (2011)

23. N.Chaimoon, C.Lertsatitthanakorn, K.Chaimoon . Performance and Economic Comparative Study of Interlocking Block and Clay Bricks Buildings, Applied Mechanics and Materials.2893-2898. (2013)

24. L. Yong, A. Esfandy,Refelctive Insulation Roof System.MU-IGBC Symposium. (2015)

25. J.Bakhteri, A.M Makhtar, S. Sambasivam, Investigation of Failure Modes in Unreinforced Brick Masonry Wall Subjected to Different Load Combination Research Vote No: 71638,UTM Skudai, Johor, Malaysia. (2004)

26. Doris, H.C.T. Kabuto, Comparative assessment of vernacular passive cooling technique for improving thermal comfort of modern terraced houses in hot-humid climate of Malaysia, Solar Energy 114.229-258 (2015)

27. M.R. Ramadhian, What do you consider a good standard deviation, Researchgate (Accessed: 14th May 2018)

28. R.B.V Ventakaram, K.S. Jagadish, Embodied energy of common and alternative building materials and technologies. Energy and Buildings 35.129-137 (2003)

29. World Weather Online. Tronoh Historical Weather, Perak, MY. (Accessed: 14th May 2018) 